\title{
A FORÇA DOS PRECEDENTES JUDICIAIS NO PROCESSO PENAL: UMA BUSCA PELA IGUALDADE E SEGURANÇA JURÍDICA
}

\section{THE FORCE OF JUDICIAL PRECEDENTS IN CRIMINAL PROCEDURE: A PURSUIT FOR EQUALITY AND LEGAL CERTAINTY}

\author{
${ }^{1}$ Bianca Garcia Neri \\ ${ }^{2}$ Barbara Gaeta Dornellas de Lima
}

\section{Resumo}

O presente trabalho é fruto de uma análise da atuação de juízes e tribunais em matéria criminal, diante da sua relevância quando da possibilidade de intervenção do Estado na esfera de liberdade individual. A problemática que deu origem à pesquisa traduz-se no fato de que casos semelhantes estão recebendo tratamento jurídico distinto, por meio de decisões particularizadas. Dessa forma, parte-se da hipótese de que é possível a aplicação do sistema de precedentes judiciais, conforme disciplinado no novo Código de Processo Civil, ao processo penal, notadamente por ser um mecanismo capaz de garantir tratamento igualitário e segurança jurídica aos jurisdicionados.

Palavras-chave: Precedentes judiciais, Processo penal, Estabilidade das decisões, Igualdade, Segurança jurídica

\section{Abstract/Resumen/Résumé}

This paper is the result of an analysis of the approach of judges and courts in criminal matter, in view of this relevance about the possibility of state intervention in the sphere of individual freedom. The issue that has brought up this research is based on the fact that similar cases are receiving different legal treatment through individualized judicial decisions. Thus, this article sustains the hypothesis that is possible to apply the judicial precedents system, as disciplined in the new Civil Procedure Code, to criminal procedure, especially as an instrument able to ensure equal treatment and legal certainty for jurisdictional.

Keywords/Palabras-claves/Mots-clés: Judicial precedents, Criminal procedure, Stability of decisions, Equality, Legal certainty

\footnotetext{
${ }^{1}$ Professora e Mestre em Direito Público e Evolução Social pela Universidade Estacio de Sá, UNESA - RJ, (Brasil). É Advogada.

${ }^{2}$ Especialista em Direito Processual Civil pela Escola da Magistratura do Estado do Rio de Janeiro, EMERJ - RJ, (Brasil). Advogada. E-mail: babigaeta@ hotmail.com
} 


\section{INTRODUÇÃO}

O sistema jurídico da civil law, em uma concepção pós-positivista, confere ao magistrado grande relevância quando da aplicação concreta da lei, tendo em vista sua atividade interpretativa, buscando melhor adequar as normas jurídicas ao caso concreto. ${ }^{1}$

Contudo, a referida atuação jurisdicional muitas vezes conduz a decisões demasiadamente subjetivas e particularizadas ao conferir tratamento distinto a hipóteses fáticas semelhantes, acarretando em grave insegurança jurídica. ${ }^{2}$ Quando da interpretação e aplicação concreta da lei, o magistrado projeta suas impressões pessoais, considerando circunstâncias não normatizadas ${ }^{3}$, permitindo, assim construções que nem sempre guardam correspondência entre si.

Atento a essa questão, o novo Código de Processo Civil (CPC/2015) incorporou expressamente a teoria dos precedentes judiciais, trazendo importantes mecanismos de aperfeiçoamento de uniformização e estabilização da jurisprudência pátria, como forma de assegurar a efetividade do processo e a coerência do ordenamento jurídico.

No que tange ao processo penal, são recorrentes os casos em que não há consenso na interpretação da lei ${ }^{4}$ por parte de juízes e tribunais, ensejando em uma aplicação desigual do Direito. A relevância da questão reside no fato de que a ausência

\footnotetext{
${ }^{1}$ O pós-positivismo surge na segunda metade do século XX como uma forma de reaproximar o Direito de valores morais relevantes ao homem e à sociedade. Ultrapassado o modelo estritamente formalista, o novo paradigma permite ao magistrado a interpretação e aplicação da lei a partir da análise do caso concreto à luz dos princípios, possibilitando, assim a retomada da racionalidade prática do Direito, antes rechaçada pelo positivismo. Assim, o juiz não mais está em posição de neutralidade perante o Direito, possuindo papel relevante na busca pela construção e concretização da justiça (GOMES, 2008).

2 A segurança na aplicação da lei pressupõe uma uniformidade interpretativa do Direito, de modo que seja possível identificar casos que guardam semelhança entre si e aplicar-lhes solução jurídica equânime, resguardando, portanto, o tratamento igualitário. Assim, "Tal obra de criação não pode, porém, insista-se, desbordar para o arbítrio, estando antes sujeita a limites, que não podem ser transpostos para alcançar o fundo do direito, na norma legal contido, em clara violação ao princípio da tripartição dos Poderes, com a transmudação do juiz em legislador positivo, via da criação de um direito alternativo, capaz de carrear insegurança para o direito das partes no processo e o comprometimento de todo um ordenamento jurídico." (PEREIRA, 2002, p.112).

3 O magistrado, ao interpretar a lei para aplicá-la ao caso concreto, carrega consigo suas experiências,

sentimentos e convicções, ou seja, elementos que não estão presentes na norma e que irão se refletir na decisão judicial. Oliveira (1997, p. 87) destaca que "[...] o juiz é, necessariamente, um ser político, carrega para os autos todas as suas angústias, seus preconceitos, suas convicções, sua ideologia."

4 Segundo Mendes (2003, p.102) “A interpretação é vista como um instrumental pelo qual se explicita o 'verdadeiro' significado da norma jurídica. Não interessa o conteúdo da norma e sim a interpretação que se dá a ele, porque vale o que está implícito. Daí uma disputa permanente, que é comum em nosso meio jurídico, pela maior autoridade interpretativa de determinada norma. Não interessam os fatos, mas sim as interpretações e só quem está no topo da pirâmide é quem sabe de tudo, inclusive o significado de cada segmento desigual."
} 
de isonomia e previsibilidade das decisões judiciais interfere diretamente na esfera de liberdade individual, além de não estabelecer limites precisos à atuação do Estado. ${ }^{5}$

Nesse contexto, a problemática que se coloca na presente pesquisa é se há ou não a possibilidade de adotar o sistema dos precedentes judiciais, conforme estabelecido no novo CPC, ao Direito processual penal, já que o legislador permaneceu silente no que tange à matéria.

A partir de uma metodologia descritiva, qualitativa, parcialmente exploratória e de pesquisa bibliográfica e jurisprudencial, sustenta-se a hipótese de que é possível a aplicação da nova sistemática prevista na lei processual civil aos processos criminais, notadamente por garantir igualdade e segurança jurídica aos jurisdicionados.

Assim, o trabalho tem por objetivo demonstrar que não há óbice na aplicação dos precedentes judiciais ao processo penal, na forma disciplinada pelo novo CPC, que trouxe importantes mecanismos de uniformização e estabilização da jurisprudência.

A estrutura do artigo divide-se em três partes: a primeira trata do problema da desigualdade nas decisões judiciais proferidas em processos criminais, utilizando-se hipóteses concretas para comprovar a falta de consenso e de segurança jurídica; a segunda explica o sistema dos precedentes judiciais, bem como suas técnicas de aplicação, de acordo com a disciplina do CPC/2015; a última parte traz argumentos para sustentar a possibilidade de aplicação dos precedentes ao processo penal, a despeito de não existir expressa previsão na lei.

\section{DESIGUALDADE E INSEGURANÇA JURÍDICA NO PROCESSO PENAL}

A preocupação com a garantia da igualdade há muito se apresenta em nosso sistema jurídico. Desde a primeira Constituição Republicana de 1891, já se podia perceber a relevância da questão, como expressamente previa o $\S 2^{\circ}$ de seu artigo 72 :

“Todos são iguaes perante a lei. A Republica não admitte privilegios de nascimento,

\footnotetext{
${ }^{5}$ A interferência do Estado na esfera de liberdade do indivíduo deve ocorrer de forma excepcional em casos expressa e previamente previstos em lei, garantindo a todos uma atuação minimamente segura em suas relações sociais. Trata-se de expressão da teoria do garantismo penal o qual "se propõe a estabelecer critérios de racionalidade e civilidade à intervenção penal, deslegitimando qualquer modelo de controle social maniqueísta que coloca a 'defesa social' acima dos direitos e garantias individuais." (CARVALHO; CARVALHO, 2001, p.17).
} 
desconhece fóros de nobreza, e extingue as ordens honoríficas existentes e todas as suas prerogativas e regalias, bem como os titulos nobiliarchicos e de conselho."6

O direito ao tratamento igualitário ganhou destaque também na atual Carta de 1988, que traz em seu preâmbulo a instituição de um Estado que assegure “ [...] o exercício dos direitos sociais e individuais, a liberdade, a segurança, o bem-estar, o desenvolvimento, a igualdade e a justiça como valores supremos de uma sociedade fraterna, pluralista e sem preconceitos [...]”. Dessa forma, o princípio da igualdade apresenta-se como fundamento que deve nortear a elaboração e aplicação das demais normas jurídicas, encontrando, ademais, expressa previsão no caput do artigo $5^{\circ}$ da CRFB/88, segundo o qual "Todos são iguais perante a lei, sem distinção de qualquer natureza $[\ldots] "$. 7

Tal postulado deu ensejo à distinção entre igualdade na lei, dirigida ao legislador, que está proibido de utilizar-se da lei para diferenciar aqueles que se encontram em situação equivalente e, igualdade perante a lei, destinada ao intérprete, que deverá concretizar as normas jurídicas de forma equânime em casos idênticos ou semelhantes (MENDES; COELHO; BRANCO, 2008).

A despeito da referida distinção, é possível inferir, a partir da leitura do princípio supracitado, que todo cidadão, a quem a lei encarou como igual, deve receber o mesmo tratamento quando da aplicação concreta da lei, ou seja, juízes e tribunais devem adotar o mesmo entendimento para solucionar situações fáticas semelhantes.

Nesse contexto, percebe-se que o tratamento igualitário é capaz de proporcionar a segurança que deve ser garantida pelo Estado em todas as relações jurídicas e sociais, proporcionando aos indivíduos confiança e previsibilidade. Assim, ao desempenhar a atividade jurisdicional, o magistrado deve buscar a máxima coerência e hegemonia na interpretação e aplicação concreta das leis ${ }^{8}$, sendo certo que a falta de

\footnotetext{
6 Art. 72, §2º , Constituição da República dos Estados Unidos do Brasil de 1891. A referida Carta, que teve grande influência do liberalismo norte-americano, trouxe um elenco de direitos fundamentais que marcavam a nova ordem republicana ao abolir privilégios de nascimento, foros de nobreza e ordens honoríficas, de caráter tipicamente monárquico. 7 O presente trabalho aborda a questão da igualdade em seu aspecto jurídico, ou seja, no sentido de que a lei deve ser aplicada de forma indistinta a todos os indivíduos, notadamente quando de sua concretização externada na decisão judicial.

8 A decisão judicial deve ser fruto de um sistema de distribuição de justiça coerente e uniforme, ou seja, o magistrado, diante do caso concreto, deve analisar decisões que já foram proferidas em hipóteses semelhantes, notadamente pelos tribunais superiores, evitando, assim, julgamentos demasiadamente individualizados, que fazem valer a qualquer custo a vontade do julgador.
} 
critérios razoáveis no processo decisório acarreta a insegurança na administração da justiça. ${ }^{9}$

No âmbito criminal, os postulados da igualdade e da segurança jurídica apresentam relevância ainda maior, uma vez que os indivíduos devem ter certeza sobre os limites de sua atuação e quais as possíveis consequências de seus atos. Corroborando essa lógica, o princípio da legalidade ${ }^{10}$ determina que as leis devem ser anteriores aos crimes e que a sanção penal já deve estar previamente estabelecida quando de sua concreta aplicação. $^{11}$

A questão que se coloca diz respeito à falta de observância dessas garantias por parte dos magistrados que, baseados na sistemática do livre convencimento motivado $^{12}$, proferem decisões particularizadas e que deixam o jurisdicionado em verdadeira situação de insegurança. Assim, a possibilidade de cada juiz ou tribunal decidir de forma isolada e sem vinculação a decisões anteriores gera um quadro de instabilidade que se reflete nas relações sociais, ou seja, no comportamento do cidadão perante a sociedade, tendo diminuída a segurança de seu atuar.

Destaca-se, por exemplo, a falta de consenso no que tange à aplicação do princípio da insignificância ao crime de descaminho, notadamente após a edição da Portaria 75/2012 do Ministério da Fazenda, que elevou o patamar dos débitos tributários que não são passíveis de sofrer execução físcal. ${ }^{13}$ Por um lado, há entendimento no sentido de que serão insignificantes e, portanto, atípicas, as condutas cuja sonegação de

9 "É a insopitável necessidade de poder assentar-se sobre algo reconhecido como estável, ou relativamente estável, o que permite vislumbrar com alguma previsibilidade o futuro; é ela, pois, que enseja projetar e iniciar consequentemente - e não aleatoriamente, ao mero sabor do acaso -, comportamentos cujos frutos são esperáveis a médio e longo prazo." (MELLO, 2008, p. 124).

10 Paulo Bonavides ensina que "o princípio da legalidade nasceu do anseio de estabelecer na sociedade humana regras permanentes e válidas que fossem obras da razão, e pudessem abrigar os indivíduos de uma conduta arbitrária e imprevisível da parte dos governantes. Tinha-se em vista alcançar um estado geral de confiança e certeza na ação dos titulares do poder, evitando-se assim a dúvida, a intranquilidade, a desconfiança e a suspeição, tão usuais onde o poder é absoluto, onde o governo se acha dotado de uma vontade pessoal soberana ou se reputa legibus soluto e onde, enfim, as regras de convivência não foram previamente elaboradas nem reconhecidas.” (BONAVIDES, 1994, p. 112).

11 Trata-se de expressão do princípio da legalidade em sua vertente consubstanciada pelo brocardo nullum crimen nulla poena sine lege praevia, expressamente previsto no artigo $5^{\circ}$, XXXIX da CRFB/88, segundo o qual "não há crime sem lei anterior que o defina, nem pena sem prévia cominação legal".

12 O livre convencimento motivado, ou persuasão racional, refere-se ao sistema de apreciação das provas que permite ao magistrado decidir, fundamentadamente, o processo de acordo com o juízo que fez acerca do conjunto probatório, não estando vinculado a qualquer valoração previamente atribuída às provas, como no antigo sistema da prova legal ou tarifada (NUCCI, 2014).

13 Tendo em vista a ausência de previsão legal sobre o princípio da insignificância, juízes e tribunais adotam como parâmetro o disposto no artigo 20 da Lei n.10.522/02, segundo o qual serão arquivados os autos das execuções fiscais de débitos que não ultrapassem $\mathrm{R} \$ 10.000,00$. Em 2012, a Portaria 75 do Ministério da Fazenda, elevou tal valor para $\mathrm{R} \$ 20.000,00$, dando ensejo a uma série de controvérsias e decisões divergentes. 
tributos não ultrapasse $\mathrm{R} \$ 10.000,00$, tendo em vista ser o parâmetro estabelecido pela lei, a qual não pode ser modificada por portaria ${ }^{14}$; por outro, adota-se como critério para verificação da relevância da conduta o valor de $R \$ 20.000,00$, uma vez que a portaria apenas atualizou o referido valor e, se não há interesse para fins de execução fiscal, menos ainda deve haver para aplicação de sanção penal. ${ }^{15}$

Além disso, consultando a jurisprudência dos tribunais competentes para julgar o referido delito, é possível encontrar decisões no sentido de que a prática reiterada da conduta impede a aplicação do princípio da insignificância, visto que tal benesse acabaria incentivando criminosos habituais. Entretanto, há decisões diametralmente opostas, que não levam em consideração tal fator, uma vez que apenas critérios objetivos devem ser analisados para fins de aplicação do princípio. ${ }^{16}$

Questão relevante que também enseja discrepância decisória diz respeito à aplicabilidade da Súmula 608 do Supremo Tribunal Federal ${ }^{17}$ após o advento da Lei n. 12.015/2009, a qual modificou dispositivos do Código Penal que tratam dos crimes contra a dignidade sexual (antes, denominados crimes contra os costumes). Explica-se: antes da alteração legislativa, em regra, tais crimes procediam-se mediante ação penal privada, sendo ação penal pública condicionada apenas nos casos expressamente previstos no artigo 225 do CP. Diante disso, a Corte Suprema, formulou o enunciado 608, determinando que a ação penal casos de estupro com violência real é pública incondicionada. Após 2009, o artigo 225 do referido códex passou a considerar a regra de que os crimes contra a dignidade sexual são de ação penal pública condicionada à representação do ofendido, salvo nos casos em que a vítima é menor ou pessoa vulnerável, quando então será ação penal pública incondicionada, conforme dispõe o parágrafo único do dispositivo legal.

\footnotetext{
14 Cf. STJ AgRg no REsp 1.438.967/PR. Rel. Ministro Ericson Maranho. 19 de dezembro de 2014; STJ. AgRg no REsp 1.381.935/PR. Rel. Ministro Nefi Cordeiro. 19 de dezembro de 2014; STF. HC 112.

772/PR. Rel. Ministro Ricardo Lewandowski. 21 de setembro de 2012; STF. HC 114.675/PR. Ministro Ricardo Lewandowski. 16 de setembro de 2012.

15 Cf. STJ. REsp 1.475.522/SP. Rel. Ministro Gurgel de Faria. 19 de novembro de 2014; STJ. AgRg no REsp 1.419.862/SC. Rel. Ministro Gurgel de Faria. 04 de novembro de 2014; STF. HC 120.617/PR. Rel. Ministro Rosa Weber. 19 de fevereiro de 2014; STF. HC 120.096/PR. Rel. Ministro Roberto Barroso. 04 de abril de 2014.

16 Cf. STJ. AgRg no REsp 1.300.651/PR. Rel. Ministro Ericson Maranho. 03 de novembro de 2014; STJ. AgRg no REsp 1.334.184/PE. Rel. Ministro Ericson Maranho. 03 de novembro de 2014; STF. HC 115.869/RS. Rel. Ministro Dias Toffoli. 09 de abril de 2013; STF. HC 115.514/RS. Rel. Ministro Ricardo Lewandowski. 10 de abril de 2013; STF. HC 114.548/PR. Rel. Ministra Rosa Weber. 27 de novembro de 2014.

${ }^{17}$ Supremo Tribunal Federal. Súmula 608 - No crime de estupro, praticado mediante violência real, a ação penal é pública incondicionada.
} 
Tendo em vista que a Súmula 608 do STF não foi formalmente cancelada, é possível encontrar não só julgados no sentido de que ainda deve ser aplicada ${ }^{18}$, evitando a impunidade do agressor, mas também, decisões que repudiam a sua aplicação ${ }^{19}$, visto que anterior à alteração legislativa, a qual pretendeu mesclar o interesse público do Estado em punir tais delitos e o interesse privado da vítima em resguardar a sua intimidade.

Ainda no que tange aos crimes contra a dignidade sexual, questão que também enseja decisões discrepantes versa sobre o crime do artigo 217-A do Código Penal, que prevê uma modalidade mais grave de estupro, tendo em vista a presunção de violência, diante da vulnerabilidade da vítima menor de 14 anos. A disparidade se dá no tocante à natureza dessa presunção: se absoluta, sendo, portanto, irrelevante o consentimento da vítima, ou, se relativa, quando então, o consentimento da vítima em ter conjunção carnal ou praticar outro ato libidinoso, afasta a incidência do tipo penal. É possível encontrar decisões díspares tanto no âmbito interno de um mesmo tribunal ${ }^{20}$ como no âmbito externo, entre tribunais de diferentes estados. ${ }^{21}$

As hipóteses ora mencionadas são apenas alguns exemplos do que ocorre diariamente na prática forense e que já se internalizou com certa naturalidade na cultura jurídica brasileira, onde provas de concurso público prestigiam o candidato que mais

18 Cf. STJ. HC 215.460/SC. Rel. Ministro Gilson Dipp. 13 de dezembro de 2011; STJ. REsp 1.227.746/RS. Rel. Ministro Gilson Dipp. 17 de agosto de 2011.

19 Cf. STJ. RHC 26.455/BA. Relator Ministro Felix Fischer. 26 de abril de 2010; STF. HC 102.683/RS. Rel. Ministra Ellen Gracie. 07 de fevereiro de 2011; STJ. RHC 40.719/RJ. Relator Ministro Jorge Mussi.

26 de março de 2014; STJ. HC 135.462/SP. Rel. Ministro Napoleão Nunes Maia Filho. 13 de dezembro de 2010.

20 Como exemplo, vale mencionar decisões proferidas em 2014 e 2015 no Tribunal de Justiça do Rio de

Janeiro. Entendendo pela presunção absoluta de vulnerabilidade: TJRJ. APL 0001346-50.2011.8.19.0016. Rel. Des. Marcus Basílio. 05 de maio de 2015; TJRJ. APL 0000643-94.2009.8.19.0047. Rel. Des. Siro Darlan de Oliveira. 03 de março de 2015. TJRJ. APL 0013168-78.2012.8.19.0023. Rel. Des. Carlos Eduardo Roboredo. 05 de agosto de 2014. Entendendo pela presunção relativa de vulnerabilidade: TJRJ. APL 0016253-04.2013.8.19.0002. Relator Des. Marcus Quaresma Ferraz. 28 de maio de 2014; TJRJ. APL 0016253-04.2013.8.19.0002. Relator Siro Darlan de Oliveira. 18 de fevereiro de 2014.

21 No sentido da presunção absoluta, cabe destacar as seguintes decisões dos Tribunais de Justiça dos Estados do Ceará, Maranhão e Roraima. TJCE. APL 0002403-77.2010.8.06.0056. Rel. Des. Francisco Gomes de Moura. 18 de dezembro de 2015. TJMA. APL 0006227-13.2012.8.10.0040. Rel. Des. José Bernardo Silva Rodrigues. 24 de fevereiro de 2015; TJRR. APL 0010.10.002299-4. Rel. Des. Almiro Padilha. 07 de outubro de 2014. Sustentando pela presunção relativa, é possível citar julgados dos Tribunais de Justiça dos Estados da Paraíba, São Paulo e Minas Gerais: TJPA. APL 0000022-

69.2013.815.0241. Rel. Des. Carlos Martins Beltrão Filho. 16 de fevereiro de 2016; TJSP. APL 0022411-

58.2010.8.26.0302. Rel. Des. Lauro Mens de Mello. 03 de dezembro de 2015; TJMG. APL

10144130014349001. Rel. Des. Alberto Deodato Neto. 24 de abril de 2015. 
"correntes" conhece, ou seja, aquele que melhor discorre acerca dos diversos posicionamentos adotados em decisões judiciais. ${ }^{22}$

Nas palavras de Luiz Guilherme Marinoni (MARINONI, 2009, p. 46):

Embora deva ser no mínimo indesejável, para um Estado Democrático, dar decisões desiguais a casos iguais, estranhamente não há qualquer reação a esta situação na doutrina e na praxe brasileiras. É como se estas decisões não fossem vistas ou fossem admitidas por serem inevitáveis.

Diante do importante papel desempenhado por juízes e tribunais na aplicação das leis, é imperioso que procurem interpretá-las e harmonizá-las em consonância com todo o conjunto normativo que compõe o ordenamento jurídico, bem como observar a solução adotada em casos similares, evitando assim, que o Direito se transforme em uma verdadeira loteria.

Cabe ao Estado a tutela dos bens jurídicos de maior relevância social, entretanto, seu poder de intervenção na esfera de liberdade individual não deve ficar a cargo da discricionariedade do intérprete, que varia seu entendimento casuisticamente, mesmo em hipóteses iguais. Assim, não se pode pensar em um direito penal e processual penal despidos das garantias de igualdade, conferindo-se tratamento isonômico a casos idênticos, e segurança jurídica, possibilitando aos cidadãos a mínima previsibilidade na aplicação das leis. É nesse sentido que se pretende demonstrar a relevância dos precedentes judiciais, como forma de orientação das decisões judiciais, mantendo-se a coerência do sistema.

\section{O SISTEMA DOS PRECEDENTES NO ORDENAMENTO JURÍDICO PÁTRIO E AS TÉCNICAS DE FLEXIBILIZAÇÃo}

Há alguns anos o Brasil vem anunciando novos contornos ao Direito Processual, colocando em destaque a atuação dos órgãos jurisdicionais, notadamente dos tribunais superiores. Essa nova perspectiva pretende solucionar com maior segurança jurídica, coerência, celeridade e isonomia as causas cuja relevância ultrapassa os interesses subjetivos das partes (ATAÍDE JR, 2012).

\footnotetext{
22 A construção do saber jurídico não é pautada na lógica do consenso, mas sim na lógica do contraditório, traduzida na existência de "correntes doutrinárias" que se apresentam como visões opostas acerca do mesmo objeto, servindo como fundamento para as mais variadas decisões judiciais, legitimando assim, um sistema que não prima pela igualdade jurídica (KANT DE LIMA; BAPTISTA, 2010).
} 
Em que pese a lei ser fonte primária do sistema da civil law, em uma concepção pós-positivista, não se pode mais admitir um ordenamento jurídico dissociado de qualquer interpretação jurisdicional, haja vista que a sociedade, em sua dinâmica evolutiva, passa por diversas transformações e que, por óbvio, não são acompanhadas pela lei, em decorrência da dificuldade do legislador em prever todas as situações concretas que podem ser abrangidas (MARINONI, 2009). Entretanto, a atuação interpretativa do juiz, diante do subjetivismo a ela inerente, pode acarretar nas mais variadas decisões judiciais, gerando uma verdadeira situação de insegurança e imprevisibilidade.

Diante disso, o novo Código de Processo Civil, incorporou o sistema de precedentes judiciais, definidos pela doutrina pátria como decisões judiciais tomadas à luz do caso concreto, cujo núcleo essencial pode servir como diretriz para o julgamento posterior de casos análogos (DIDIER JR; OLIVEIRA; BRAGA, 2013). Trata-se de uma tentativa de manter a coerência do sistema e a segurança jurídica aos jurisdicionados, ao determinar que casos semelhantes recebam o mesmo tratamento. ${ }^{23}$

A teoria dos precedentes foi desenvolvida a partir do sistema da common law, também conhecido como anglo-saxão e distingue-se do nosso ordenamento jurídico, da civil law, notadamente em razão das fontes do Direito, haja vista que neste, o ordenamento substancia-se basicamente em leis, abrangendo os atos normativos em geral, como decretos, resoluções e medidas provisórias e etc. Já o sistema da common law, tem natureza jurisprudencial, cuja principal fonte do Direito são os precedentes derivados dos tribunais superiores. Nesse sistema, a jurisprudência não é apenas a materialização da aplicação das leis ao caso concreto, tendo em vista que dela emanam as próprias regras do Direito.

É oportuno e positivo que o sistema jurídico pátrio seja, parcialmente, descaracterizado em prol da efetivação e modernização do Direito, aproximando-se cada vez mais do sistema da common law, que adotou a força normativa dos precedentes, tendo por escopo oferecer soluções semelhantes para questões que possuam o mesmo fundamento jurídico, evitando, assim, decisões díspares e a utilização excessiva de recursos.

\footnotetext{
23 Nesse sentido, William Burnham assevera que: "This equality of treatment in turn serves to limit bias and arbitrariness and allow parties to rely with some certainty on how the system has dealt with cases similar to theirs. (...) Since statutes can be subjetiv to differing interpretations, the rationales for a system of precedent apply with equal force to judicial decisions interpreting enacted law." (BURNHAM, 2002, p.64).
} 
Tucci (2004) explica que a teoria do stare decisis, vem da expressão latina "stare decisis et non quieta movere" que significa "mantenha-se a decisão e não se moleste o que foi decidido". A referida teoria norteia a aplicação dos precedentes na common law e determina a força obrigatória destes quando derivados dos tribunais superiores, sendo, portanto, a base da função criativa da jurisprudência. Contudo, não se pode considerar o stare decisis um princípio absoluto, posto que em qualquer sistema jurídico é preciso haver uma correspondência entre a realidade social e as regras de Direito aplicáveis.

Neste sentido, a ferramenta jurídica do overruling tem como função flexibilizar o sistema da common law, possibilitando à Corte rever, revogar ou superar as suas decisões, desde que motivadas, em virtude da modificação dos valores sociais, dos conceitos jurídicos, da tecnologia ou até mesmo em razão de erro gerador de instabilidade em sua aplicação (WAMBIER, 2009).

Outro mecanismo importante do sistema da common law é o denominado distinguishing, que é utilizado para a aplicação dos precedentes com efeito vinculante aos casos concretos, onde o juiz verifica se o caso em julgamento pode ou não ser considerado análogo ao paradigma. Se não existir similitude ou coincidência entre os fatos discutidos na ação e a tese jurídica que subsidiou o precedente ou se houver alguma peculiaridade no caso concreto que afaste a aplicação da ratio decidendi ${ }^{24}$ daquele precedente, o magistrado poderá se ater à hipótese sub judice, sem se vincular ao precedente judicial e nem ao julgamento anterior.

Assim, não obstante a noção de obrigatoriedade, os precedentes judiciais não devem ser invocados em toda e qualquer situação. Existem diversos casos em que os fatos não guardam relação de semelhança, mas exigem a mesma conclusão jurídica. Em outros, os fatos podem até ser correlatos, mas as particularidades de cada caso os tornam substancialmente diferentes.

\footnotetext{
24 A ratio decidendi é a parte do precedente que possui força vinculante, devendo ser observada quando do julgamento de casos análogos àquele objeto da decisão, tendo de conter os princípios de direito utilizados para se chegar à decisão final, ou seja, é a essência da tese jurídica suficiente para decidir o caso concreto. É indubitável a importância de se identificar a ratio decidendi ou os motivos determinantes da decisão, tendo em vista tratar-se da parte do precedente que servirá de paradigma para os casos concretos posteriores, garantindo previsibilidade e segurança na realização do direito. Não se deve confundir com o obter dictum, sendo os trechos da decisão que não são considerados essenciais ao resultado, logo, não estão vinculados aos fatos do caso concreto, ou seja, trata-se da regra de direito constante em um caso que não faz parte da sua ratio decidendi, e portanto, não obrigatório. Apesar de continuarem sem efeitos obrigatórios as referidas obiter dictum possuem forte efeito persuasivo (MARSHALL, 1997).
} 
Verifica-se que o mais importante nessa distinção é que exista a motivação, ou seja, as decisões judiciais não devem apenas se reportar aos dispositivos da lei ou aos conceitos abstratos e abertos, mas também devem expor os elementos fáticos e jurídicos em que o magistrado se apoiou para decidir. Na fundamentação das decisões judiciais, o julgador deve identificar exatamente as questões que reputou como essenciais ao deslinde da demanda, notadamente a tese jurídica escolhida. Assim, esclarece Lourenço (2011, p. 7) que: "a fundamentação será a norma geral, um modelo de conduta para a sociedade, principalmente para os indivíduos que nunca participaram daquele processo, e para os demais órgãos do Judiciário, haja vista ser legitimante da conduta presente”.

Não há dúvidas de que a Constituição Federal brasileira visa garantir uma mínima previsibilidade do resultado de determinadas ações, de modo a proporcionar aos jurisdicionados maior segurança jurídica, tanto na formação do ato jurídico, quanto no momento de se buscar a tutela jurisdicional. A previsibilidade do resultado de certas demandas não acarretará na mumificação do Poder Judiciário, visto que os tribunais poderão modificar seus precedentes, desde que o façam com a devida fundamentação.

Neste sentido, os precedentes judiciais no sistema brasileiro, objetivam alcançar a exegese que forneça essa certeza aos jurisdicionados em temas polêmicos, uma vez que ninguém estará seguro de seus direitos diante de uma jurisprudência incerta.

Ao positivar o referido instrumento, o novo códex buscou a adequação dos entendimentos jurisprudenciais em todos os níveis de jurisdição, evitando a dispersão e a intranquilidade social e, ainda, o descrédito nas decisões emanadas pelo Poder Judiciário.

\section{PRECEDENTES JUDICIAIS NO PROCESSO PENAL}

A incorporação do sistema de precedentes pelo novo Código de Processo Civil reforça a ideia de que não é possível admitir decisões judiciais particularizadas e que conferem tratamento diferenciado a casos semelhantes. Entretanto, é importante notar que na esfera criminal, até o presente momento, não houve qualquer alteração no Código de Processo Penal incorporando a referida sistemática, o que gera dúvidas quanto à possibilidade de aplicação dos dispositivos previstos no novo CPC. 
Em uma primeira análise, cabe lembrar que o Direito Processual Civil e o Direito Processual Penal são ramificações que provém de uma raiz comum, qual seja, a Teoria Geral do Processo, uma vez que compartilham dos mesmos conceitos de jurisdição, ação, processo, defesa, coisa julgada, competência, preclusão, juiz natural, recurso, dentre outros. ${ }^{25}$ Ademais, a CRFB/88 ao tratar da competência legislativa da União (artigo 22, I, CRFB/88) ${ }^{26}$ e dos demais entes federativos (artigo 24, XI, $\mathrm{CRFB} / 88)^{27}$, referiu-se ao Direito Processual como um todo, não fazendo qualquer divisão em ramos específicos.

Tendo em vista o reconhecimento da jurisprudência como fonte supletiva ${ }^{28}$ do Direito Processual, o sistema de precedentes judiciais deve ser encarado como tal e aplicado de forma indistinta tanto em matéria cível como em matéria criminal. ${ }^{29}$ Além disso, ainda que não se reconheça o caráter unitário do Direito Processual, é possível encontrar na doutrina entendimento considerando a jurisprudência como fonte do Direito Processual Penal. ${ }^{30}$

Nesse contexto, ressalta-se que o artigo $3^{\circ}$ do CPP admite a aplicação analógica - respeitando-se o princípio que veda o uso da analogia in mallam partem como meio de integração da lei, de modo que, havendo omissão legislativa sobre determinada hipótese fática, é possível recorrer a preceito que regula caso semelhante.

\footnotetext{
25 Cintra, Grinover e Dinamarco (2012, p. 57) destacam que "Como é una a jurisdição, expressão do poder estatal igualmente uno (v. esp. cap. 12), também é o direito processual, como sistema de princípios e normas para o exercício da jurisdição. $\mathrm{O}$ direito processual como um todo decorre dos grandes princípios e garantias constitucionais pertinentes e a grande bifurcação entre processo civil e processo penal corresponde apenas a exigências pragmáticas relacionadas com o tipo de normas jurídico- substanciais a atuar nos domínios do direito comparado já se podem invocar exemplos de regulamentação unitária do direito processual civil com o direito processual penal, em um só Código (Codex iuris cononici, de1917; Código processual sueco de 1942; Código do Panamá e Código de Honduras)".

26 Art. 22. Compete privativamente à União legislar sobre: I - direito civil, comercial, penal, processual,

eleitoral, agrário, marítimo, aeronáutico, espacial e do trabalho. (grifo nosso)

27 Art. 24. Compete à União, aos Estados e ao Distrito Federal legislar concorrentemente sobre: [...] XI - procedimentos em matéria processual. (grifo nosso)

28 "O vocábulo fonte designa o lugar donde dimana alguma coisa, pelo que fonte do direito é o lugar de onde provém a norma jurídica que ainda não existia na sociedade.” (ALVIM, 2012, p. 199).

29 A despeito da divergência conceitual entre jurisprudência - conjunto de decisões genericamente considerado - e precedente - decisão relevante tomada em determinado caso particular capaz de vincular decisões posteriores - é possível perceber uma aproximação entre os institutos, notadamente no que tange à chamada "jurisprudência consolidada" - decisões reiteradas sobre um mesmo assunto - que exerce forte influência sobre julgamentos futuros. Assim, se a jurisprudência pode ser encarada como fonte do Direito, os precedentes merecem ainda mais tal qualidade, diante de sua força e autoridade, independente do reconhecimento legislativo.

30 Nesse sentido, conferir AVENA, 2014; GOMES, 2005.
} 
Como exemplo é possível citar a aplicação do artigo 543-A do CPC/1973 que disciplina a repercussão geral nos Recursos Extraordinários, bem como o artigo 87 do CPC/1973, com correspondência no artigo 43 do CPC/2015, que trata da estabilização da competência - perpetuatio jurisdicionis. Destaca-se, ainda, a aplicação do artigo 28 do CPP ao Processo Civil, remetendo-se o processo ao Procurador Geral quando o magistrado discordar da decisão do Ministério Público em não intervir como fiscal da ordem nos casos previstos no artigo 82 do CPC/1973, com correspondência no artigo 178 do CPC/2015.

Assim, tendo em vista que o processo penal também padece de falta de uniformidade e coerência nas decisões judiciais, cabe adotar o sistema dos precedentes, utilizando-se de forma analógica os dispositivos do novo CPC que regulam a matéria. Trata-se de verdadeira analogia in bonam partem, visto que confere tratamento igualitário e consequente segurança jurídica ao jurisdicionado.

Para além dos casos de aplicação analógica, há dispositivos no Código de Processo Penal que expressamente invocam a aplicação de normas processuais civis, como nos casos de depósito e administração de bens arrestados (artigo 139, CPP), citação por hora certa (artigo 362, CPP) e homologação de sentença penal estrangeira (artigo 790, CPP), demonstrando a possibilidade de diálogo entre as fontes normativas processuais.

Interessante notar que, quando o legislador não admite o intercâmbio de normas o faz de forma expressa, como se pode verificar no artigo 12 , §2 ${ }^{\circ}$, VIII do CPC/2015 que exclui os processos criminais da regra que determina a observância por juízes e tribunais da ordem cronológica de conclusão do processo para julgamento. No que tange ao sistema de precedentes judiciais, com previsão expressa nos artigos 926, 927, 928 e 976, todos do novo CPC, o legislador não fez qualquer menção à inaplicabilidade aos processos de competência criminal.

Da mesma forma, há casos em que não se admite a aplicação das normas processuais civis ao processo penal, pois o Código de Processo Penal disciplina a matéria de forma diversa. A título de exemplo é possível citar a inaplicabilidade do artigo 219 do CPC/2015, que determina a contagem dos prazos em dias úteis, pois o CPP em seu artigo 798 prevê que a contagem seja contínua, ou seja, em dias corridos.

No mesmo sentido, não é possível aplicar a regra do artigo 220 do novel códex, que assegura a suspensão dos prazos durante as férias, uma vez que conflita com o disposto 
no artigo 797 do CPP, que autoriza a prática de atos ainda que no período de férias. Assim, tendo em vista que não há qualquer norma processual penal disciplinando de forma diversa do novo CPC sobre a questão dos precedentes, não há que se falar em impedimento legislativo para tal.

Além disso, a regra dos precedentes prevista no CPC/2015 não esvazia o livre convencimento motivado do juiz previsto no artigo 155 do CPP, tendo em vista que o respeito aos precedentes está no campo da interpretação da lei, que visa uniformizar o entendimento, não interferindo na forma de apreciação das provas pelo magistrado.

Mesmo tratando-se de interpretação da lei, o magistrado tem seu espaço de liberdade no momento da decisão, conforme disciplina o artigo 489, §1 ${ }^{\circ}$, VI do CPC/2015 ao possibilitar que o juiz deixe de aplicar súmula, jurisprudência ou precedente citado pela parte, se demonstrar que se trata de caso distinto (distinguishing) ou a superação do entendimento invocado (overruling).

Diante dos argumentos ora esposados, é possível perceber que não há qualquer incompatibilidade do sistema de precedentes judiciais com o processo penal, tendo em vista não haver dispositivo específico em matéria criminal disciplinando de forma diversa, tampouco vedando expressamente a aplicação das normas processuais civis que tratam da questão. Além disso, o CPP possibilita a aplicação analógica, legitimando o intercâmbio entre normas de processo civil e normas de processo penal, o que se corrobora quando da recomendação expressa do legislador criminal.

A despeito da ausência de previsão legal, o diálogo entre as fontes normativas processuais, notadamente em matéria de uniformização e estabilidade da jurisprudência, apresenta grande relevância para assegurar a igualdade e a segurança jurídica, postulados tão importantes quando o que está em discussão é a liberdade individual.

Enxerga-se, na força vinculante dos precedentes judiciais, uma forma de garantir a segurança e previsibilidade de que tanto necessitam os cidadãos em suas relações sociais, o que somente poderá ser alcançado quando hipóteses fáticas semelhantes receberem tratamento jurídico igualitário. "Nada adianta a lei quando o cidadão não sabe o que esperar dos juízes.” (MARINONI, 2009, p. 25). 


\section{CONCLUSÃO}

A partir da análise acerca da falta de consenso nas decisões judiciais que conferem tratamento distinto a hipóteses fáticas similares, buscou-se demonstrar a premente necessidade de uniformização interpretativa, sustentando-se a hipótese de que é possível aplicar ao processo penal o sistema de precedentes judiciais, na forma prevista pelo novo CPC, principalmente por se tratar de mecanismo capaz de assegurar a igualdade na aplicação concreta da lei.

Embora o Direito brasileiro seja baseado essencialmente na civil law, a incorporação dos precedentes judiciais nos aproxima de um Direito (common law) que busca manter a coerência do sistema pela observância de decisões anteriormente proferidas em casos similares, servindo como orientação para solucionar casos futuros, possibilitando assim, a uniformização da jurisprudência.

Notadamente no âmbito do direito processual penal, que deve assegurar o respeito às garantias e liberdades individuais, os precedentes poderão servir como auxílio na redução da discricionariedade do juiz em sentido amplo, haja vista que ao reconstruir o ordenamento jurídico, permitirá maior racionalidade e universalidade das razões de decidir.

A independência dos juízes e tribunais dependerá cada vez mais de decisões com caráter universal, aplicáveis para todas as situações similares, deixando de lado os casuísmos que a jurisprudência estimula e que fazem dos nossos tribunais uma verdadeira loteria.

O sistema dos precedentes judiciais poderá fortalecer a responsabilidade com o tratamento isonômico, promovendo igualdade, maior coerência do sistema jurídico e da interpretação do Direito. Diante da necessidade da sociedade de ter resguardada segurança jurídica em todas as relações, o que ganha ainda mais relevância quanto de trata de matéria criminal, o sistema de precedentes possibilita alcançar tal pressuposto e, ainda, garantir eficácia, previsibilidade e rapidez na prestação jurisdicional. 


\section{REFERÊNCIAS}

ALVIM, J. E. Carreira. Teoria geral do processo. 15. ed. rev. e atual. Rio de Janeiro: Forense, 2012.

ATAIDE JR, Jaldemiro Rodrigues de. Uma proposta de sistematização da eficácia temporal dos precedentes diante do projeto de novo CPC. O projeto do Novo Código de Processo Civil. Estudos em homenagem ao Professor José Joaquim Calmon de Passos. Salvador: Juspodivm, 2012.

AVENA, Norberto. Processo penal esquematizado. 6. ed. rev., atual. e ampl. São Paulo: Método, 2014.

BONAVIDES, Paulo. Ciência política. São Paulo: Malheiros, 1994.

BURNHAM, William. Introduction to the law and legal system of the United States. 3. ed. St. Paul, MN: West Group, 2002.

CARVALHO, Salo de; CARVALHO, Amilton Bueno de. Aplicação da pena e garantismo. Rio de Janeiro: Lumen Iuris, 2001.

CINTRA, Antônio Carlos de Araújo; GRINOVER, Ada Pellegrini; DINAMARCO, Cândido Rangel. Teoria geral do processo. 28. ed. São Paulo: Malheiros, 2012.

DIDIER JR, Fredie; OLIVEIRA, Rafael; BRAGA, Paula. Curso de Direito Processual Civil. Salvador: Juspodivm, 2013.

GOMES, Luiz Flávio. Direito processual penal. São Paulo: RT, 2005.

GOMES, Sérgio Alves. Hermenêutica constitucional: um contributo à construção do Estado Democrático de Direito. Curitiba: Juruá, 2008.

MARSHALL, Geoffrey. What is binding in a precedent. In: MACCORMICK, D. Neil;

SUMMERS, Robert S. Interpreting precedents: a comparative study. Ashgate: Dartmouth, 1997.

MARINONI, Luiz Guilherme. Aproximação crítica entre as jurisdições de civil law e common law e a necessidade de respeito aos precedentes no Brasil. Revista da Faculdade de Direito UFPR. Curitiba, n. 49, jun. 2009, p. 11-58.

MELlo, Celso Antônio Bandeira de. Curso de direito administrativo. São Paulo: Malheiros, 2008.

MENDES, Gilmar Ferreira; COELHO, Inocêncio Mártires; BRANCO, Paulo Gustavo Gonet. Curso de direito constitucional. 2. ed. rev. e atual. São Paulo: Saraiva, 2008. 
MENDES, Regina Lúcia Teixeira. O princípio da isonomia à brasileira: Igualdade é tratar desigualmente os desiguais. Dissertação (Mestrado em Ciências Jurídicas), Universidade Gama Filho, Rio de Janeiro. 2003.

NUCCI, Guilherme de Souza. Manual de processo penal e execução penal. 11. ed. rev. e atual. Rio de Janeiro: Forense, 2014.

OLIVEIRA, Regis Fernandes de. O juiz na sociedade moderna. São Paulo: FTD, 1997.

PEREIRA, Áurea Pimentel. A obra de criação do Direito pelo Juiz na interpretação das leis. Revista da Emerj. Rio de Janeiro, v.5, n.18, 2002.

TUCCI, José Rogério Cruz e. Precedente Judicial como Fonte do Direito. São Paulo: Revista dos Tribunais, 2004.

WAMBIER, Teresa Arruda Alvim (coord.). Estabilidade e adaptabilidade com os objetivos do direito: civil law e common law. In: Revista de Processo. São Paulo: Revista dos Tribunais, n.172, jun. 2009.

\section{Consultas da internet:}

BRASIL. Constituição da República dos Estados Unidos do Brasil (1891). Disponível em:<http://www.planalto.gov.br/ccivil_03/Constituicao/Constituicao91.htm>. Acesso em: 10 mar. 2016.

Constituição da República Federativa do Brasil (1988). Disponível em: $<$ http://www.planalto.gov.br/ccivil_03/Constituicao/Constituicao.htm>. Acesso em: 10 mar. 2016.

. Lei n. 12.015, de 07 de agosto de 2009. Disponível em: <http://www.planalto.gov.br/ccivil_03/_ato2007-2010/2009/lei/112015.htm>. Acesso em: 11 mar. 2016.

. Ministério da Fazenda. Portaria n. 75, de 22 de março de 2012. Disponível em:<http://www.fazenda.gov.br/acesso-a

informacao/institucional/legislacao/2012/portaria75>. Acesso em: 11 mar. 2016.

- Supremo Tribunal Federal. Súmula 608. Disponível em: $<\mathrm{http} / / /$ www.stf.jus.br/portal/cms/verTexto.asp?servico=jurisprudenciaSumula\&pagina =sumula_601_700>. Acesso em: 11 mar. 2016.

. Código de Processo Civil. Lei n. 13.105 de 16 de março de 2015. Disponível em: <http://www.planalto.gov.br/ccivil_03/_ato2015-2018/2015/lei/113105.htm>. Acesso em: 17 mar. 2016. 
Disponível em: <http://www.planalto.gov.br/ccivil_03/DecretoLei/Del3689Compilado.htm>. Acesso em: 17 mar. 2016.

Superior Tribunal de Justiça. AgRg no REsp 1.438.967/PR. Relator Ministro Ericson Maranho. 19 de dezembro de 2014. Disponível em: $<\mathrm{http} / / / \mathrm{www}$. stj.jus.br/SCON/jurisprudencia/toc.jsp?tipo_visualizacao=null\&processo= 1438967\&b=ACOR\&thesaurus=JURIDICO >. Acesso em: 11 mar. 2016.

. Superior Tribunal de Justiça. AgRg no REsp 1.381.935/PR. Relator Ministro Nefi Cordeiro. 19 de dezembro de 2014. Disponível em: $<\mathrm{http}: / /$ www.stj.jus.br/SCON/jurisprudencia/toc.jsp?tipo_visualizacao=null\&processo= 1381935\&b=ACOR\&thesaurus=JURIDICO >. Acesso em: 11 mar. 2016.

. Supremo Tribunal Federal. HC 112. 772/PR. Relator Ministro Ricardo Lewandowski. 21 de setembro de 2012. Disponível em: $<$ http://www.stf.jus.br/portal/jurisprudencia/listarJurisprudencia.asp?s1=\%28112772\%2 ENUME\%2E+OU+112772\%2EACMS\%2E\%29\&base=baseAcordaos\&url=http://tinyu rl.com/kfkpe5n>. Acesso em: 11 mar. 2016.

. Supremo Tribunal Federal. HC 114.675/PR. Relator Ministro Ricardo Lewandowski. 16 de setembro de 2012. Disponível em: <http://www.stf.jus.br/portal/jurisprudencia/listarJurisprudencia.asp?s1=\%28114675\%2 ENUME\%2E+OU+114675\%2EACMS\%2E\%29\&base=baseAcordaos\&url=http://tinyu rl.com/oqjus2l>. Acesso em: 11 mar. 2016.

. Superior Tribunal de Justiça. REsp 1.475.522/SP. Relator Ministro Gurgel de Faria. 19 de novembro de 2014. Disponível em: $<\mathrm{http}: / / \mathrm{www}$. stj.jus.br/SCON/jurisprudencia/toc.jsp?tipo_visualizacao=null\&processo= 1475522\&b=ACOR\&thesaurus=JURIDICO >. Acesso em: 11 mar. 2016.

Superior Tribunal de Justiça. AgRg no REsp 1.419.862/SC. Relator Ministro

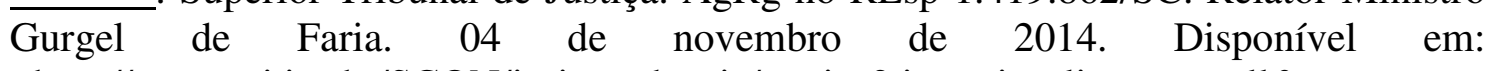
$<$ http://www.stj.jus.br/SCON/jurisprudencia/toc.jsp?tipo_visualizacao=null\&processo= 1419862\&b=ACOR\&thesaurus=JURIDICO >. Acesso em: 11 mar. 2016.

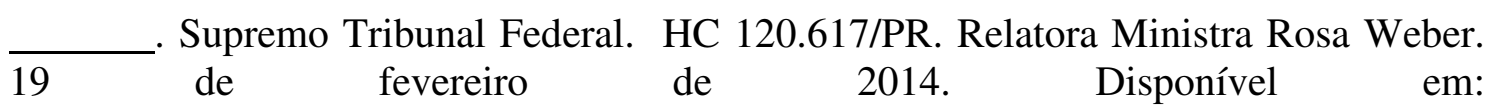
$<$ http://www.stf.jus.br/portal/jurisprudencia/listarJurisprudencia.asp?s1=\%28120617\%2 ENUME\%2E+OU+120617\%2EACMS\%2E\%29\&base=baseAcordaos\&url=http://tinyu rl.com/nrlqtby>. Acesso em: 11 mar. 2016.

Supremo Tribunal Federal. HC 120.096/PR. Relator Ministro Roberto Barroso. 04 de abril de 2014. Disponível em: $<$ http://www.stf.jus.br/portal/jurisprudencia/listarJurisprudencia.asp?s1=\%28120096\%2 ENUME $\% 2 \mathrm{E}+\mathrm{OU}+120096 \% 2 \mathrm{EACMS} \% 2 \mathrm{E} \% 29 \&$ base=baseAcordaos\&url=http://tinyu rl.com/14ds2ca>. Acesso em: 11 mar. 2016. 
. Superior Tribunal de Justiça. AgRg no REsp 1.300.651/PR. Relator Ministro Ericson Maranho. 03 de novembro de 2014. Disponível em: $<\mathrm{http} / / /$ www.stj.jus.br/SCON/jurisprudencia/toc.jsp?tipo_visualizacao=null\&processo= 1300651\&b=ACOR\&thesaurus=JURIDICO>. Acesso em: 11 mar. 2016.

Superior Tribunal de Justiça. AgRg no REsp 1.334.184/PE. Relator Ministro Ericson Maranho. 03 de novembro de 2014. Disponível em: $<$ http://www.stj.jus.br/SCON/jurisprudencia/toc.jsp?tipo_visualizacao=null\&processo= 1334184\&b=ACOR\&thesaurus=JURIDICO >. Acesso em: 11 mar. 2016.

Supremo Tribunal Federal. HC 115.869/RS. Relator Ministro Dias Toffoli. 09 de abril de 2013. Disponível em: <http://www.stf.jus.br/portal/jurisprudencia/listarJurisprudencia.asp?s1=\%28115869\%2 ENUME\%2E+OU+115869\%2EACMS\%2E\%29\&base=baseAcordaos\&url=http://tinyu rl.com/p17p92h >. Acesso em: 11 mar. 2016.

Supremo Tribunal Federal. HC 115.514/RS. Relator Ministro Ricardo Lewandowski. 10 de abril de 2013. Disponível em: $<$ http://www.stf.jus.br/portal/jurisprudencia/listarJurisprudencia.asp?s1=\%28115514\%2 ENUME\%2E+OU+115514\%2EACMS\%2E\%29\&base=baseAcordaos\&url=http://tinyu rl.com/mhb9yn7>. Acesso em: 11 mar. 2016.

. Supremo Tribunal Federal. HC 114.548/PR. Relatora Ministra Rosa Weber. 27 de novembro de 2014. Disponível em: <http://www.stf.jus.br/portal/jurisprudencia/listarJurisprudencia.asp?s1=\%28114548\%2 ENUME\%2E+OU+114548\%2EACMS\%2E\%29\&base=baseAcordaos\&url=http://tinyu rl.com/k5sa4hm>. Acesso em: 11 mar. 2016.

. Superior Tribunal de Justiça. HC 215.460/SC. Relator Ministro Gilson Dipp. 13 de dezembro de 2011. Disponível em: $<\mathrm{http} / / / \mathrm{www}$. stj.jus.br/SCON/jurisprudencia/toc.jsp?tipo_visualizacao=null\&processo= 215460\&b=ACOR\&thesaurus=JURIDICO >. Acesso em: 11 mar. 2016.

Superior Tribunal de Justiça. REsp 1.227.746/RS. Relator Ministro Gilson Dipp. 17 de agosto de 2011. Disponível em: $<$ http://www.stj.jus.br/SCON/jurisprudencia/toc.jsp?tipo_visualizacao=null\&processo= 1227746\&b=ACOR\&thesaurus=JURIDICO >. Acesso em: 11 mar. 2016.

. Superior Tribunal de Justiça. RHC 26.455/BA. Relator Ministro Felix Fischer. 26 de abril de 2010. Disponível em: $<$ http://www.stj.jus.br/SCON/jurisprudencia/toc.jsp?tipo_visualizacao=null\&processo= 26455\&b=ACOR\&thesaurus=JURIDICO $>$. Acesso em: 11 mar. 2016.

. Supremo Tribunal Federal. HC 102.683/RS. Relator Ministro Ellen Gracie. 07 de fevereiro de 2011. Disponível em: $<\mathrm{http}: / /$ www.stf.jus.br/portal/jurisprudencia/listarJurisprudencia.asp?s1=\%28102683\%2 ENUME\%2E+OU+102683\%2EACMS\%2E\%29\&base=baseAcordaos\&url=http://tinyu rl.com/mbkljqj>. Acesso em: 11 mar. 2016. 
. Superior Tribunal de Justiça. RHC 40.719/RJ. Relator Ministro Jorge Mussi. $\overline{26}$ de março $\quad$ de $2014 . \quad$ Disponível em:<http://www.stj.jus.br/SCON/jurisprudencia/toc.jsp?tipo_visualizacao=null\&processo= 40719\&b=ACOR\&thesaurus=JURIDICO >. Acesso em: 11 mar. 2016.

Superior Tribunal de Justiça. HC 135.462/SP. Relator Ministro Napoleão Nunes Maia Filho. 13 de dezembro de 2010. Disponível em: $<\mathrm{http}: / / \mathrm{www}$. stj.jus.br/SCON/jurisprudencia/toc.jsp?tipo_visualizacao=null\&processo= 135462\&b=ACOR\&thesaurus=JURIDICO $>$. Acesso em: 11 mar. 2016.

- Tribunal de Justiça do Estado do Rio de Janeiro. APL 000134650.2011.8.19.0016. Relator Des. Marcus Basílio. 05 de maio de 2015. Disponível em: <http://www1.tjrj.jus.br/gedcacheweb/default.aspx?UZIP=1\&GEDID=0004C8E0642B 389F3AC3C95805AD3754475DC50361503933 >. Acesso em: 19 mar. 2016.

Tribunal de Justiça do Estado do Rio de Janeiro. APL 000064394.2009.8.19.0047. Relator Des. Siro Darlan de Oliveira. 03 de março de 2015. Disponível em: <http://www1.tjrj.jus.br/gedcacheweb/default.aspx?UZIP=1\&GEDID=0004BCB9D750 583C41F626524AF17AA913ABC50350643C38>. Acesso em: 19 mar. 2016.

. Tribunal de Justiça do Estado do Rio de Janeiro. APL 001316878.2012.8.19.0023. Relator Des. Carlos Eduardo Roboredo. 05 de agosto de 2014. Disponível

em: <http://www1.tjrj.jus.br/gedcacheweb/default.aspx ?UZIP=1\&GEDID=000408D7E3E2 9005CEEF9A9E548B5D84DE4EC503202A6019> . Acesso em: 19 mar. 2016.

. Tribunal de Justiça do Estado do Rio de Janeiro. APL 001625304.2013.8.19.0002. Relator Des. Marcus Quaresma Ferraz. 28 de maio de 2014. Disponível em: <http://www1.tjrj.jus.br/gedcacheweb/default.aspx ?UZIP=1\&GEDID=0004905358739 B2BDF8019647502C65E6231C50311192655>. Acesso em: 19 mar. 2016.

Tribunal de Justiça do Estado do Rio de Janeiro. APL 001625304.2013.8.19.0002. Relator Des. Siro Darlan de Oliveira. 18 de fevereiro de 2014. Disponível em: <http://www1.tjrj.jus.br/gedcacheweb/default.aspx?UZIP=1\&GEDID=00041EF9DFF2 B06D569069D5D2000AEC2B7EC5026021331F>. Acesso em: 19 mar. 2016.

Tribunal de Justiça do Estado do Ceará. APL 0002403-77.2010.8.06.0056. Relator Des. Francisco Gomes de Moura. 18 de dezembro de 2015. Disponível em: $<$ http://esaj.tjce.jus.br/cjsg/getArquivo.do?cdAcordao=3091298\&cdForo=0\&vlCaptcha $=\mathrm{QvdVy}>$. Acesso em: 19 mar. 2016.

Tribunal de Justiça do Estado do Maranhão. APL 000622713.2012.8.10.0040. Relator Des. José Bernardo Silva Rodrigues. 24 de fevereiro de 2015. Disponível em: <http://jurisprudencia.s3.amazonaws.com/TJ- 
MA/attachments/TJMA_APL_0528752014_aef92.pdf?Signature=kuRL\%2F4Se6JRCS euM3Nxg\%2BPNojFc\%3D\&Expires=1458415691\&AWSAccessKeyId=AKIAIPM2X EMZACAXCMBA\&response-content-type=application/pdf\&x-amz-meta-md5hash=d36359fe8f27b33e77d7495ca86dd584>. Acesso em: 19 mar. 2016.

. Tribunal de Justiça do Estado de Roraima. APL 0010.10.002299-4. Relator Des. Almiro Padilha. 07 de outubro de 2014. Disponível em: <http://www.tjrr.jus.br/juris/detalhes.xhtml?juris=11969> . Acesso em: 19 mar. 2016.

. Tribunal de Justiça do Estado da Paraíba. APL 0000022-69.2013.815.0241. Relator Des. Carlos Martins Beltrão Filho. 16 de fevereiro de 2016. Disponível em:<http://tjpb-jurisprudencia-dje.tjpb.jus.br/dje/2016/2/18/57942174-a994-4aec-85adf0a9fa7ccdb0.pdf>. Acesso em: 19 mar. 2016.

. Tribunal de Justiça do Estado de São Paulo. APL 002241158.2010.8.26.0302. Relator Des. Lauro Mens de Mello. 03 de dezembro de 2015. Disponível em: <http://jurisprudencia.s3.amazonaws.com/TJ-SP/attachments/TJSP_APL_00224115820108260302_c931b.pdf?Signature=0rthDkLD6RJF\%2FppMFC5 HcEUK8bE\%3D\&Expires=1458420057\&AWSAccessKeyId=AKIAIPM2XEMZACA XCMBA\&response-content-type=application/pdf\&X-amz-meta-md5hash=431c8460b51430b5d5fc1525e2127ae9>. Acesso em: 19 mar. 2016.

. Tribunal de Justiça do Estado de Minas Gerais. APL 10144130014349001. Relator Des. Alberto Deodato Neto. 24 de abril de 2015. Disponível em: $<$ http://jurisprudencia.s3.amazonaws.com/TJMG/attachments/TJMG_APR_101441300 14349001_9226f.pdf?Signature=4HG5kd7xE9F7\%2BNkwI39a0d4\%2BBpE\%3D\&Exp ires $=1458414743 \& A W S A c c e s s K e y I d=A K I A I P M 2 X E M Z A C A X C M B A \& r e s p o n s e-$ content-type=application/pdf\&x-amz-meta-md5hash=9652659210a63604487e671f495c3691>. Acesso em: 19 mar. 2016.

KANT DE LIMA, Roberto, BAPTISTA, Bárbara Gomes Lupetti. O desafio de realizar pesquisa empírica no direito: uma contribuição antropológica. In: ENCONTRO DA ABCP, 7, 2010. Recife. Disponível em: <http://www.uff.br/ineac/?q=o-desafio-derealizar-pesquisa- empirica-no-direito>. Acesso em: 09 mar. 2016.

LOURENÇO, Haroldo. Precedente Judicial como Fonte do Direito: algumas considerações sob a ótica do Novo CPC. In: Revista Eletrônica Temas Atuais de Processo Civil, vol.1, n.6, dez. 2011. Disponível em: <http://www.temasatuaisprocessocivil.com.br/edicoes-anteriores/53- v1-n-6-dezembrode-2011->. Acesso em: 20 mar. 2016. 